\title{
Organizational Resilience: As Mediating Effect of Organizational Culture and Organizational Performance
}

Dianawati Suryaningtyas ${ }^{1}$, Achmad Sudiro ${ }^{2}$, Eka A. Troena ${ }^{3}$, Dodi W. Irawanto ${ }^{4}$ Faculty of Economy and Business, Brawijaya University, Malang, Indonesia ${ }^{1,2,3,4}$

fe.diana@yahoo.co.id ${ }^{1}$, dodi.wi@ub.ac.id ${ }^{4}$

\begin{abstract}
Disruption technology emerge when the flow of innovation in digital cannot be retained. Organizational resilience needed to cope with these changes and challenges. This research paper aims to contribute to knowledge by examining the mediating role of organizational resilience in between of organizational culture and organizational performance. The result revealed that organizational culture has a significant effect on organizational performance. While it was mediated by organizational resilience, therelationship between organizational resilience and organizational performance was not significant. But overall, the result revealed that organizational resilience partially played as a mediating role between organizational culture and organizational performance. The implication of this study that the General Manager and Human Resource Manager appropriately understand the importance of organizational culture in integrating with organizational resilience to achieve superior organizational performance as a strategy to anticipate disruption technology. Limitation of this study is small sample size so that for future study should use a larger sample size in a different kind of business.
\end{abstract}

Keywords: Organizational Resilience, Organizational Culture, Innovation, DisruptionTechnology

\section{Introduction}

Nowadays, digital innovation is coming in the age of industrial revolution 4.0. The development of economy and business enters a new era that foster difficulties, disruptiontechnology andeven crisis to organizations. The business has shifted from the established ones to the different ways of business run by millennial generation, in which innovation is the main factor in these changes. In regard to these conditions, organizations who still want to survive must take action and make changes accordingly. How organizations respond and take proactive action to this condition? This research paper is important for organizations who still want to exist in this era.

Recently, resilience has become the main interest for academicians and practitioners due to emerging of many turbulent external environments. The concept of resilience has been growing significantly in many disciplines as the need for coping many external disturbances in order to 
become survive and maintain sustainability. Resilience has been defined many different ways in the literature, depends on its characteristic as multi-discipline and multi-dimensional. Derived from ecology, resilience defines as the ability of a complex system to return to stability after disruption [1]

In the human resource management issues, research in the context of organizational resilience and its relationship with other variables is still rare. This paper aims to contribute to knowledge by examiningthe mediation role of organizational resilience between organizational culture and organizational performance in the hotel industry in Indonesia.

\section{Literature Review}

\subsection{Organizational Resilience}

Within the organizational context, the literature has two perspectives on what organizational resilience means [2]. The first perspective defines organizational resilience as an ability to rebound from unexpected and adverse situations [3]. Organization deliberate efforts are to react and reestablish a strong fit with avoiding and limiting dysfunctional systems [2] Organizational resilience that focuses on restore or bounces back to the benchmark after a crisis is also called reactive or operational perspective [4]The second perspective of organizational resilience defined as a capability of organization to absorb, develop newcapability and create other opportunities to grow, and engage transformative activities to preventdisruptive and other disturbances that potentially threaten organizational survival [5]; [6]; [2], [2] This second point of view, which is also called a strategic perspective(Valikangas and Romme, 2012), organizational resilience goes beyond the rebound and re-establish from the crisis. Strategic organizational resilience thrives because it has the dynamic capability to anticipate disruptive and other unexpected challenges.Both perspectives of strategic resilience as well as operational resilience are needed for the success of the organization [7]; [2] The decision of determining whether to act operational or strategic perspective of organizational resilience, it depends on the maturity level of the organization itself [8]This research synthesizes the maturity of organization, operational and strategic organizational resilience.

\subsection{Organizational Culture}

In recent years, understanding the role of organizational culture as a strategic resource or asset is important for organizations. Culture defined many ways by researchers, one definedas "something to do with the people and the unique quality and style of the organization" [9]

Organizational culture defined as a combination of norm, beliefs, values and behavior patterns that shape the core identity of an organization [10]management styles and processes [11]; [12]).It can differentiate [13] organization to competitors. Organizational culture plays a key role in determining strategy formulation, leadership style, working climate, and organizational behavior and processes ([14]manifested by managers and leaders.

Organizational culture is difficult to measure. Researchers used the concept of Competing Values Framework (CVF) to measure it quantitatively. This research used CVF developed by [10]by identifying four characteristics of culture which are positively associated with performance and effectiveness of organizations, namely: adaptability, mission, involvement, and consistency.Denison's concept is supported by Gregory et al. [15]research that organizations not only need a strong culture but also have a balanced combination of those four characteristics that deliver flexibility in thinking. 


\subsection{Organizational Performance}

Organizational performance is the most important component to measure success as well as failure level of the organization. Organizational performance is used in the empirical study as an outcome of many variables that influence it. Organizational performance defined as an indicator to measure how does the extent the organization reaches its goal [5][16].

Balanced scorecard approach used to measure organizational performance in their research in the hotel industry, and taken financial perspective out of the questionnaires because of difficulties in accessing the real data. This research adopts this concept in using the indicators. [16]

\subsection{Organizational Culture,Organizational Resilience, and Organizational Performance}

The relationship between organizational culture and organizational performance had been reported a significant link between a particular type of strong culture and superior financial performance[16]; [17]; [18]. Recent research mentioned that organizational culture had significantly affected organizational performance [19]; [20]; [21] This study is to test the hypothesis :

H1. Organizational culture has positivelyan effect on organizational performance. [22 ]The relationship between culture and resilience is that resilience means as cultural adaptability to cope with external disruptions. While Parsons described resilience and culture are tightly linked. The relationship between organizational resilience and organizational performance had been proven by Carden et al. [22] that organizational resilience enhanced organizational performance in the financial aspect. [23] had investigated resilience and its effect on organizational performance. This study is to test the mediating role of organizational resilience between organizational culture and performance, herewith the hypothesis :

H2. Organizational culture has positively an effect on organizational performance mediated by organizational resilience.Based on the above hypotheses, the conceptual model can be figured out as follows:

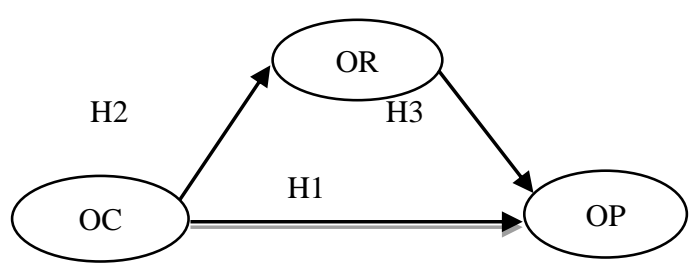

Fig. 1. Conceptual Model

OC $=$ Organizational Culture

$\mathrm{OR}=$ Organizational Resilience

$\mathrm{OP}=$ Organizational Performance

\section{Method}

We use software WarpPLS 3 version to process and analyze data. This software uses two models to analyze data, such as measurement model and structural model.

The research conducted in 3-star hotels, resorts and premium guest houses in two towns in East Java, Indonesia. The technique sampling method was purposive sampling. An amount of 76 set of questionnaires administered to General Managers and Human Resource Managers or the persons 
in charge in those positions of each company. The 70 set of returned questionnaires were valid for analyzing.

Composite reliability and Cronbach's Alpha are significant and reliableif all the instruments used in the research shouldbe above the criteria of $>0.70$ [23] To test convergent validity, the values of Average Variance Extracted (AVE) shouldbe above the criteria of $>0.50$. To test collinearity vertically as well as laterally, the result of Full collinearity of all variables should be below the criteria of $<3.3$. The R-Squared coefficient is above 0.5 indicated the model is good. [24]

\section{Result and Discussion}

\subsection{Measurement Model Analysis}

Measurement model analysis was to test reliability and the validity of instruments used in this research.

Table 1. Latent Variable Coefficients

\begin{tabular}{|l|c|c|c|}
\hline & OC & OR & OP \\
\hline Composite Reliability & 0.926 & 0.894 & 0.937 \\
\hline Cronbach's Alpha & 0.913 & 0.866 & 0.926 \\
\hline Aver.Var. Ext.(AVE) & 0.514 & 0.501 & 0.576 \\
\hline Full Collinearity (VIF) & 2.202 & 1.488 & 2.337 \\
\hline R-Squared & & 0.317 & 0.629 \\
\hline Q-Squared & & 0.316 & 0.624 \\
\hline
\end{tabular}

As described in Table 1, the results of composite reliability and Cronbach's Alpha were all significant and reliablebecause all instruments used in this research were above the criteria of> 0.70 [23]. Average Variance Extracted (AVE) were allabove the criteria of $>0.50$. The result of Full collinearity demonstrated that all variables were below the criteria of $<3.3$ so that the model was free of multicollinearity. the R-Squared coefficient of organizational performance was 0.629 indicated the model was good. It meant that organizational performance construct $62.9 \%$ could be explained by organizational cultureand organizationalresilience. To measure predictive validity, this research indicated a good result because the value was more than zero. Discriminant validity was valid and adequate, as described in Table 2.

Table 2. Latent Variable Correlations

\begin{tabular}{|l|c|c|c|}
\hline & OC & OR & OP \\
\hline $\begin{array}{l}\text { Organizational } \\
\text { Culture (OC) }\end{array}$ & $(0.717)$ & 0.509 & 0.727 \\
\hline Organizational Resilience (OR) & 0.509 & $(0.698)$ & 0.550 \\
\hline Organizational Performance (OP) & 0.727 & 0.550 & $(0.759)$ \\
\hline
\end{tabular}

Overall, the analysis of the measurement model was reliable and valid.

\subsection{Structural Model Analysis}

The structural model analysis was to test the hypothesis, particularly the direct and indirect relationship between organizational culture and organizational performance. The first step, we tested whether organizational cultureinfluence organizational performance directly was to test hypothesis H1.The result showed in Figure 1 that organizational resilience has significant effect on 
organizational performance (coefficient $=0.76, \mathrm{P}<0.01$ and values of $\mathrm{R}^{2}=0.58$ ). Hypothesis $\mathrm{H} 1$ was supported.

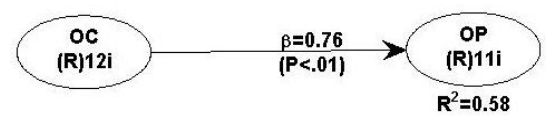

Fig, 2. Direct Effect Model

Then, we tested organizational resilience as mediating constructs.PLS result shown in Figure 2 , mentioned that organizational culturehad positively andsignificantlyan effect onorganizational performance (coefficient $=0.59, \mathrm{P}<0.01 ; \mathrm{R}^{2}=0.63$ ). Other results demonstrated that organizational culture has significantly effect organizational resilience (coefficient $=0.56, \mathrm{P}<$ 0.01 , while organizational resilience has not significantly affect organizational performance (coefficient $=0.28, \mathrm{P}=0.05)$. So that, estimation result of an indirect effect on organizational culture to organizational performance declined from 0,76 to 0.59 but still significant $(\mathrm{P}<0.01)$. This result revealed that partial mediation happened on the effect of organizational culture on organizational performance. This partial mediation revealed that organizational resilience was not the only mediator in the relationship between organizational culture and organizational performance, yet other mediators [25] Therefore, hypothesis H2 was also supported.

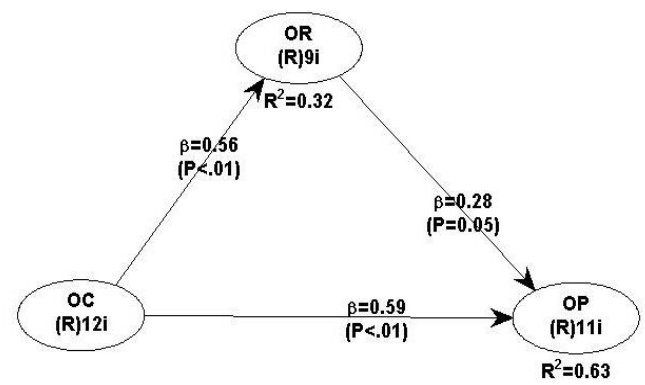

Fig. 3. Indirect Effect Model

The practical significance of this research was to estimate whether statistical findings exist or not in population, and it can be measured by effect size [26]. Effect size organizational resilience to organizational performance was 0.177 , and according to Cohen [27]. this value was adequate for practical significance.

The result of model fit indices and $\mathrm{P}$ values mentioned that Average Path Coefficient (APC) = $0.478, \mathrm{P}<0.001$, Average R-Squared $(\mathrm{ARS})=0.473, \mathrm{P}<0.001$, and Average Variance Inflation Factor $(\mathrm{AVIF})=1.586$, good if $<5$, are all significant and fulfilled the criteria. This result was concluded that the model was fit and supported by data.

The result of testing hypothesis 1 reveals that organizational culture has positively and significantly an effect on organizational performance. This result supports the statements of some researchers [19]; [20]; [21]Organizational culture as a resource can enhance organizational performance in which the financial aspect was excluded from the indicators of the balanced scorecard. While the result of testing hypothesis 2 reveals that organizational culture has positively an effect on theorganizational performance with partial mediating role by 
organizational resilience. Partially, the result ofanalyzing the relationship between organizational culture and organizational performance supports Parsons [28] On the other hand, the result of analysing the relationship between organizational resilience and organizational performance was not significant. This is understood that this result does not support Carden et al. [29]because themeasurement of organizational performance was excluded financial aspect. But overall, the result of analyzing organizational resilience as a mediating role as stated in hypothesis 2 was positive and significant.

\section{Conclusions}

In conclusion, the effect of organizational resilience on the relationship between organizational cultur and organizational performance is partially mediated. Understanding the conceptof thisresearch, fully mediated might be achieved when the indicator of the financial aspect is also included in the measurement of organizational performance. The implicationfor General Managersand HumanResource Managers is that to understand the importance of organizational culture to be integrated inexecuting organizational resilience in order to cope disruptive technology and other disturbances. Limitations ofthis studyaresmall samplesize and excluded financial aspect to measure organizational performance.

\section{Acknowledgments}

We acknowledge sincere thanks to DRPM KEMENRISTEK DIKTI who have given the grant to conduct this research.

\section{References}

[1] R. Bhamra, S. an. B. Dani, and K., "Resilience: the concept, a literature review, and future directions," International Journal of Production Research, vol. 49, no. 18, pp. 5375-5393, 2011.

[2] C. A. Lengnick-Hal, T. E. Beck, and M. L. Lengnick-Hall, "Developing a capacity for organizational resilience through strategic human resource management," 255, Journal homepage, vol. 21, no. 243, 2011.

[3] D. Robb, Building resilientorganizations. OD, 2000.

[4] L. A. da. R. Välikangas and G.L., "Buildingresilience capabilities at 'Big Brown Box,", Inc., Strategy \& Leadership, vol. 40, no. 4, pp. 43-45, 2012.

[5] G. an. V. Hamel and L., "The quest for resilience," Harvard Business Review, vol. 81, no. 9, pp. 52-63, 2003.

[6] J. J. Jamrog, J. E. I. McCann, J. M. Lee, C. L. Morrison, J. W. Selsky, and M. Vickers, Agility and resilience in the face of continuous change, the American Management Association. 2006.

[7] G. Hamel, "Competition for competence and inter-partner learning within international strategic alliances,” Strategic Management Journal, vol. 12, pp. 83-103, 1991.

[8] J. Valastro, "Organisational resilience: a position paper for critical infrastructure," Commonwealth of Australia, pp. 1-41, 2011.

[9] R. H. Kilmann, M. J. Saxton, and R. an. A. Serpa, Gaining Control of the Corporate Culture. Jossey-Bass, San Francisco, CA, 1985.

[10] D. R. Denison, S. da. G. Haaland, and P., "culture and organizational effectiveness: is Asia different from the rest of the world?," Organizational Dynamics, vol. 33, pp. 98-109, 2004. 
[11] Z. Aycan et al., "Impact of culture on human resource management practices: a ten-country comparison," Applied Psychology: International Review, vol. 49, no. 1, pp. 192-220, 2000.

[12] E. Schein, Organizational culture. American, 1990.

[13] C. an. C. O'Reilly and J.A., "Culture as social control: corporations, cults, and commitment, in Staw, B.M.and," in Research in Organizational Behavior, vol. 18, L. Cummings, Ed. Stamford, CT: JAI Press, 1996, pp. 287-365.

[14] J. Combs, Y. Liu, A. an. K. Hall, and D., "How much do high-performance work practices matter? A meta-analysis of their effects on organizational performance," Personnel Psychology, vol. 59, pp. 501-28, 2006.

[15] B. T. Gregory, S. G. Harris, A. A. Armenakis, and C. L. Shook, "Organizational culture and effectiveness: a study of values, attitudes, and organizational outcomes," J. Bus. Res, vol. 62, no. 7, pp. 673-679, 2009.

[16] T. J. an. W. Peters and R.H., In Search of Excellence. New York, NY: Harper \& Row, 1982.

[17] J. P. Kotter and J. L. and Heskett, Corporate Culture and Performance. New York, NY: The Free Press, 1992.

[18] J. B. Sorensen, The strength of corporate culture and. 2002.

[19] Z. Rashid, M. an. J. Sambasivan, and J., "The influence of corporate culture and organizational commitment on performance," The Journal of Management Development, vol. 22, no. 7/8, pp. 708-728, 2003.

[20] R. Mannion, H. T. da. M. Davies, and M.N., "Cultural characteristics of 'high' and 'low' performing hospitals," Journal of Health Organization Management, vol. Vol., pp. 431439, 2005.

[21] N. A., P. Atkinson, and P. Foroudi, Influence of national culture and balanced organizational culture on the hotel industry's performance, International Journal of Hospitality Management, Published by Elsevier Ltd. This is an open-access article under the CC BY-NC-ND license. 2017.

[22] C. L. L., T. Maldonado, and O. R. Boyd, “Organizational resilience: A look at McDonald's in the fast food industry", Article in Press, Organizational Dynamic. Http://dx.doi.org/10.1016/j.orgdyn.2017.07.0020090-2616/@ Elsevier Inc, 2017.

[23] J. C. Nunnally, Psychometric theory, 1967. New York: McGraw Hill.

[24] N. Kock, "Using WarpPLS in E-collaboration Studies: What If I Have Only One Group and One Condition?," International Journal of e-Collaboration, vol. 9, no. 3, pp. 1-12, 2013.

[25] R. M. Baron and D. and Kenny, "The Moderator-Mediator Variable Distinction in," Social Psychological Research: Conceptual, Strategic, and Statistical Considerations, Journal of Personality and SocialPsychology, vol. 51, no. 6, pp. 1173-1182, 1986.

[26] M. Sholihin, R. Pike, M. Mangena, and J, and Li, 2011.

[27] J. Cohen, A Power Primer. Psychological Bulletin, vol. 112, pp. 155-159, 1992.

[28] D. Parsons, “Organizational resilience: Parsons argues that a modern organization's ability to survive and prosper against the flow-on effects of natural disasters willdepend on its resiliencecapacity,Australian Journal ofEmergency," Management, vol. 25, no. 2, pp. 18-20, 2010.

[29] C. R. Carter, “A framework of supply chain management: Moving toward new theory," International Journal of Physical Distribution \& Logistics Management, vol. 38, no. 5, pp. 360-387., 2008. 